\title{
Pengelolaan Panen Kelapa Sawit (Elaeis guineensis Jacq.) Pelantaran Agro Estate, Kota Waringin Timur, Kalimantan Tengah
}

\section{Harvest Management of Oil Palm (Elaeis guineensis Jacq..) in Pelantaran Agro Estate, Kota Waringin Timur, Center Borneo}

\author{
Fajar Dianto, Darda Efendi", dan Ade Wachjar
}

\author{
"Departemen Agronomi dan Hortikultura, Fakultas Pertanian, Institut Pertanian Bogor \\ (Bogor Agricultural University), Jl. Meranti, Kampus IPB Darmaga, Bogor 16680, Indonesia \\ Telp.\&Faks. 62-251-8629353 e-mail agronipb@indo.net.id \\ *Penulis untuk korespondensi: dardaefendi@yahoo.com
}

Disetujui 6 November 2017/Published online 14 November 2017

\begin{abstract}
The activity was held in Pelantaran Agro Estate (PAGE), Kota Waringin Timur, Center Borneo started from February $14^{\text {th }} 2011$ until Juny 14 ${ }^{\text {th }} 2011$. The purpose of the activity is analyze the harvest management on the plantation of Oil Palm. Harvest management of Oil Plam is important in the effort to achieve a high quantity and quality of Palm Oil. The primary data were obtained by following whole activities in this plantation, observations in the field, interviews, and direct or indirect discussions with staff. The secondary data were obtained by management reports. Based on observations during the activity at PAGE can be concluded that already have a good understanding of the criteria of ripe fruit. This can be seen by unripe fruits harvested 0\%, 1.5\% under ripe, over ripe 4.9\%, 1.7\% abnormal and $91.9 \%$ ripe fruit. But there are still mistakesby harvester such as long stalk that is still more than $2.5 \mathrm{~cm}$, unpicked fruit still 77 fruits/ ha, and unharvested bunch. The process of transporting the fruit at PAGE is good enough. It can be seen by speeding up the process of transport of TBS (Fresh Bunch) and fruits to PKS (Oil Palm factory) using contractor assistance transporting the fruit so that no untransported fruit.
\end{abstract}

Keywords : Harvest management of Oil Plam, High quantity and quality of Palm Oil, Oil Plam

\section{ABSTRAK}

Kegiatan yang dilaksanakan di Pelantaran Agro Estate (PAGE), Kota Waringin Timur, Center Borneo dimulai dari 14 Februari 2011 hingga 14 Juni 2011. Tujuan kegiatan ini adalah menganalisa pengelolaan panen pada perkebunan Kelapa Sawit. Pengelolaan panen Kelapa Sawit penting dalam upaya mencapai kuantitas dan kualitas minyak kelapa sawit yang tinggi. Data primer diperoleh dengan mengikuti keseluruhan kegiatan di perkebunan ini, pengamatan di lapangan, wawancara, dan diskusi langsung atau tidak langsung dengan staf. Data sekunder diperoleh dari laporan manajemen. Berdasarkan pengamatan selama kegiatan di PAGE dapat disimpulkan bahwa sudah memiliki pemahaman yang baik tentang kriteria buah masak. Ini bisa dilihat dengan buah mentah yang dipanen 0\%, 1,5\% di bawah matang, lebih matang 4,9\%, 1,7\% abnormal dan 91,9\% buah matang. Namun masih ada kesalahan dengan pemanen seperti tangkai panjang yang masih lebih dari $2,5 \mathrm{~cm}$, buah yang tidak dikutip masih 77 buah / ha, dan tandan yang tidak dipanen. Proses pengangkutan buah di PAGE sudah cukup baik. Hal itu bisa dilihat dengan mempercepat proses pengangkutan TBS (Fresh Bunch) dan buah-buahan ke PKS (pabrik kelapa sawit) dengan menggunakan bantuan kontraktor pengangkutan buah sehingga tidak ada buah yang tidak ditranspor.

Kata kunci : Manajemen panen Kelapa Sawit, Kualitas dan kuantitas tinggi di Kelapa Sawit, Kelapa Sawit 


\section{PENDAHULUAN}

Kelapa sawit (Elaeis guineensis Jacq.) dari famili Palmae merupakan salah satu sumber minyak nabati. Potensi kelapa sawit di Indonesia sangat besar, penyebaran perkebunan kelapa sawit di Indonesia saat ini sudah berkembang di 22 propinsi. Luas perkebunan kelapa sawit di Indonesia dari tahun ke tahun terus meningkat. Luas kebun kelapa sawit pada tahun 2009 adalah 8248328 ha dan meningkat pada tahun 2010 menjadi 8430026 ha. Produksi juga terus meningkat seiring bertambahnya luas perkebunan kelapa sawit. Produksi kelapa sawit pada tahun 2007 sebesar 19324293 ton dan meningkat pada tahun 2009 menjadi 19760011 (Direktorat Jenderal Perkebunan, 2010).

Tanaman kelapa sawit memiliki banyak kegunaan. Hasil tanaman ini dapat digunakan pada industri pangan, tekstil (bahan pelumas), kosmetik, farmasi dan biodiesel. Selain itu, limbah dari pabrik kelapa sawit seperti sabut, cangkang, dan tandan kosong kelapa sawit juga dapat dimanfaatkan sebagai bahan bakar dan pupuk organik (Fauzi et al., 2008).

Kelapa sawit sebagai tanaman penghasil minyak kelapa sawit (CPO - crude palm oil) dan inti kelapa sawit (PK - palm kernel) merupakan salah satu primadona tanaman perkebunan yang menjadi sumber penghasil devisa non -migas bagi Indonesia. Produksi CPO Indonesia mengalami peningkatan cukup pesat dari tahun 1998 yaitu sebesar 5.1 juta ton meningkat menjadi 16.8 juta ton pada tahun 2007 dan menjadikan Indonesia sebagai negara penghasil CPO nomor satu terbesar di dunia (Arianto, 2008). Pada tahun 2009 total ekspor produk kelapa sawit dan turunannya mencapai 21,2 juta ton dengan nilai US\$11,6 milyar (Direktorat Jenderal Perkebunan, 2010).

Salah satu aspek dalam budidaya kelapa sawit yang mempengaruhi hasil produksi kelapa sawit secara langsung adalah pemanenan. Keberhasilan panen akan menunjang pencapaian produktivitas tanaman kelapa sawit. Kelapa sawit sudah mulai mengeluarkan manggar pada umur 3 sampai 4 tahun dan pada umur 8 sampai 11 tahun telah menghasilkan lebih dari 20 ton tandan buah segar (TBS)/ha/tahun. Pemanenan dilakukan setelah tandan berumur 5 -6 bulan. Kelapa sawit dapat dipanen secara ekonomis sampai berumur 25 tahun (Pahan, 2008).

Lubis (1992) menyatakan bahwa keberhasilan pemanenan dan produksi kelapa sawit sangat bergantung pada bahan tanam, tenaga pemanen, peralatan panen, kelancaran transportasi, organisasi pemanenan, keadaan areal, insentif yang disediakan, dan lain-lain. Selanjutnya Mangoensoekarjo dan Semangun (2006) menambahkan bahwa panen meliputi pemotongan tandan buah matang, pengutipan brondolan, pemotongan pelepah, pengangkutan hasil ke tempat pengumpulan hasil (TPH), dan pengangkutan hasil ke pabrik. Faktor-faktor yang mendukung keberhasilan panen adalah persiapan panen, kriteria matang panen, rotasi panen, sistem panen, sarana panen, pengawasan panen, dan pengangkutan tandan buah, yang semuanya berpengaruh nyata baik terhadap kuantitas maupun kualitas minyak yang akan diperoleh. Setiap aspek merupakan kombinasi yang tidak terpisahkan satu sama lain. Dengan demikian, penataan manajemen panen di perkebunan kelapa sawit yang baik sangat diperlukan.

Kegiatan ini secara umum bertujuan untuk meningkatkan pengetahuan, keterampilan kerja dan pengalaman lapangan dalam pengelolaan perkebunan kelapa sawit, baik secara teknis maupun manajerial. Kegiatan ini secara khusus bertujuan untuk meningkatkan kemampuan professional penulis dalam pengelolaan pemanenan tandan buah segar di perkebunan kelapa sawit.

\section{METODE PENELITIAN}

Kegiatan penelitian dilaksanakan di Pelantaran Agro Estate, Desa Pelantaran, Kecamatan Cempaga Hulu, Kota Waringin Timur, Kalimantan Tengah selama 4 bulan mulai Februari sampai Juni 2011.

Metode penelitian yang digunakan adalah melaksanakan seluruh kegiatan yang sudah berjalan di perusahaan, baik aspek teknis di lapangan maupun aspek manajerial pada berbagai tingkatan pekerjaan mulai dari karyawan harian lepas (KHL), pendamping mandor sampai dengan pendamping asisten afdeling. Kegiatan di lapangan sebagai pekerja harian lepas selama satu bulan, menjadi pendamping mandor selama satu bulan, dan menjadi pendamping asisten divisi selama dua bulan. Selama melakukan kegiatan penelitian penulis mencatat prestasi kerja dan semua pekerjaan yang dilakukan dalam jurnal kegiatan harian.

Pada bulan pertama sebagai pekerja harian lepas penulis melakukan semua pekerjaan yang dijadwalkan mulai dari pemeliharaan bibit di pembibitan, penyisipan tanaman, pemeliharaan tanaman (pangendalian gulma, pemupukan, dan penunasan) hingga pemanenan. Pada bulan kedua penulis mendampingi mandor dengan tugas melaksanakan instruksi dari atasan (asisten divisi). Pada bulan ketiga dan empat penulis bertugas 
sebagai pendamping asisten divisi. Pada saat itu penulis mempelajari tugas-tugas yang dilakukan seorang asisten divisi.

Selama kegiatan penelitian berlangsung topik khusus yang sudah dilaksanakan dalam penelitian adalah manajemen panen kelapa sawit pada salah satu afdeling di Perkebunan. Kegiatan yang dilakukan adalah menentukan jumlah pemanen, kriteria panen, rotasi panen, kerapatan panen, sistem panen, pelaksanaan panen, kualitas panen, upah dan panen, organisasi panen, administrasi, sarana dan prasarana panen, dan pengangkutan hasil panen.

Pengumpulan data dan informasi yang diperlukan dilakukan pada saat penelitian berlangsung. Pengumpulan data meliputi pengumpulan data primer dan pengumpulan data sekunder. Data primer yang diamati adalah jumlah pemanen, kriteria panen, rotasi panen, kerapatan panen, sistem panen, pelaksanaan panen, kualitas panen, upah dan denda panen, administrasi, sarana dan prasarana panen, dan pengangkutan hasil panen. Pengumpulan data primer dilakukan dengan pengamatan secara langsung di lapangan dan wawancara dengan mandor dan asisten. Data sekunder diperoleh dari laporan menejemen (bulanan, triwulan, semesteran, tahunan) yang tersedia di kantor kebun. Data sekunder yang mendukung pelaksanaan teknik lapangan meliputi data curah hujan, kondisi tanaman, peta lokasi kebun, keadaan tanah dan iklim, data produksi dan produktivitas serta data yang terkait dengan pemanenan. Pengamatan yang sudah dilakukan terutama terhadap aspek-aspek yang berhubungan dengan pemanenan yaitu :

1. Kriteria panen

Pengamatan dilakukan dengan cara mengikuti 5 pemanen pada dua kemandoran yang dipilih secara acak. Pada setiap pemanen diambil 15 tanaman sampel secara acak dengan 3 kali ulangan yang dilakukan pada saat penulis menjadi asisten afdeling dan asisten mandor. Data diperoleh dengan mengamati jumlah brondolan yang jatuh ke tanah sebelum TBS dipanen oleh pemanen sesuai dengan peraturan perusahaan.

2. Tenaga kerja panen

Data jumlah tenaga kerja panen diperoleh dengan melakukan wawancara dengan mandor dan asisten kebun dan mengamati secara langsung jumlah pekerja saat apel pagi dilaksanakan dan kemampuan kerja dalam satu tahun dengan menggunakan data dari perusahaan yang dilakukan pada saat penulis menjadi pendamping asisten afdeling dan pendamping mandor sehingga mendapatkan efisiensi tenaga kerja panen dalam perusahaan.

\section{Pelaksanaan panen}

Pelaksanaan panen diamati dengan mengikuti pemanen dan mengamati bagaimana pola pemanen melakukan panen seperti bagaimana cara panen dan pola panen yang dilakukan pada saat penulis menjadi pendamping asisten.

4. Kerapatan panen

Pengamatan dilakukan dengan cara memilih blok secara acak. Kemudian dalam blok tersebut dipilih $10 \%$ pokok dari total populasi secara acak untuk diamati yang dilakukan pada saat penulis menjadi asisten afdeling dan asisten mandor. Data diperoleh dengan cara mengamati jumlah tandan matang dari total pohon yang diamati. Angka kerapatan panen diperoleh dengan rumus berikut.

Kerapatan Panen $=\frac{\text { jumlah tandan matang }}{\text { jumlah pohon yang diamati }} \times 100 \%$

5. Kualitas panen

Parameter yang diamati adalah jumlah buah matang panen, buah mentah dipanen, berondolan dan panjang gagang janjang. Data diperoleh dengan melakukan pengamatan pada 4 TPH (tempat pengumpulanhasil) dan 1 ha setiap 5 pemanen pada dua kemandoran yang dipilih secara acak pada saat panen tersebut yang dilakukan pada saat penulis menjadi pendamping asisten afdeling dan pendamping mandor.

6. Sarana panen

Data diperoleh dengan melakukan wawancara dengan mandor dan asisten kebun dan pengamatan langsung di lapangan efisiensi sarana dan prasarana yang mendukung kegiatan panen yang dilakukan pada saat penulis menjadi pendamping asisten afdeling.

7. Pengangkutan TBS hasil panen

Pengamatan dilakukan dengan mengikuti secara utuh proses pengangkutan TBS hingga sampai ke pabrik. Selain itu, data juga diperoleh melalui wawancara dengan mandor dan asisten kebun yang dilakukan pada saat penulis menjadi pendamping asisten afdeling. Parameter yang diamati adalah lama pengangkutan dari awal sampai ke pabrik, jumlah pekerja, jumlah TBS yang diangkut, cara menyusun TBS di dalam angkutan.

8. Administrasi dan denda

Pengamatan yang dilakukan adalah mencari data tentang upah dan denda bagi pekerja. Data diperoleh dengan menggunakan data dari perusahaan dan wawancara bersama mandor, asisten, dan kepala administrasi yang dilakukan pada saat penulis menjadi pendamping asisten afdeling. 
Hasil kegiatan pengamatan berupa data primer dan data sekunder dengan berbagai peubah akan dianalisis dengan menggunakan metode analisis deskriptif, persentase (\%) dan nilai ratarata yang digunakan sebagai bahan perbandingan dengan studi pustaka dan norma-norma baku tentang budidaya kelapa sawit.

\section{HASIL DAN PEMBAHASAN}

\section{Keadaan Umum}

Lokasi kebun Pelantaran Agro Estate (PAGE) terletak di Desa Pelantaran, Kecamatan Cempaga Hulu, Kota Waringin Timur, Provinsi Kalimantan Tengah. Letak geografis Kebun Pelantaran Agro Estate terletak pada $112.95^{\circ}$ $113.01^{0}$ BT dan $2.02^{0}-2.11^{0}$ LS. Kondisi lahan kebun kebun Pelantaran Agro Estate (PAGE) mempunyai topografi datar hingga bergelombang. Kelas lereng $0-8 \quad \%$ (datar) dan $\quad 9-15 \%$ (begelombang). Lahan di kebun PAGE termasuk lahan kelas S2 berdasarkan kesesuaian kelas lahan. Kebun PAGE berdasarkan survey terdapat 4 jenis tanah, yaitu ultisol (podsolik), inceptisol, histosol (gambut), dan entisol (pasir). Keadaan iklim dikebun PAGE menurut klasifikasi iklim Schmidth-Ferguson termasuk tipe A (sangat basah). Curah hujan rata-rata per tahun selama empat tahun terakhir (tahun 2007-2010) adalah 3 $150.1 \mathrm{~mm} /$ tahun, rata- rata bulan kering satu bulan dan rata-rata bulan basah 11 bulan.

Luas areal yang diusahakan di kebun PAGE pada budget poduksi 2011 adalah 2697 ha, yang terdiri atas tanaman mengasilkan tahun tanam 2004 (739 ha), tahun tanam 2005 (507 ha), tahun tanam 2006 (108 ha), tahun tanam 2007 (405 ha), dan tahun tanam 2008 (38 ha). Kebun PAGE terdiri atas 4 divisi. Berdasarkan sumber bibitnya, tanaman kelapa sawit yang diusahakan di kebun PAGE adalah varietas Tenera. Jarak tanam yang dipakai adalah $9.2 \mathrm{~m} \times 9.2 \mathrm{~m} \times 9.2 \mathrm{~m}$ dengan bentuk segitiga samasisi. Kebun PAGE menggunakan beberapa jenis bibit yang ditanam antara lain, ASD/Costarica, Marihat V, PPKS, Socfindo, dan PNG.

\section{Pemanenan}

Panen merupakan kegiatan memotong tandan buah yang sudah matang optimum dari pohon, mengutip berondolan, mengumpulkan dan mengangkut buah ke tempat pengumpulan hasil (TPH) hingga pengangkutan buah ke pabrik kelapa sawit (PKS). Tujuan dari kegiatan panen adalah produktivitas tinggi dan kehilangan produksi (losses) seminimal mungkin. Menurut
Sunarko (2007) potensi produksi kelapa sawit ditentukan oleh beberapa faktor diantaranya jenis atau varietas (tenera merupakan jenis yang kandungan minyaknya tinggi) yang menentukan produktivitas per hektar, umur tanaman (berat tandan rata-rata tanaman tua lebih besar dibandingkan tanaman muda), dan curah hujan (curah hujan setahun $2500 \mathrm{~mm}$ atau lebih meningkatkan potensi produksi hingga 100\%). Produksi Kebun Pelantaran Agro Estate berdasarkan data produksi kantor kebun dari tahun 2007 hingga tahun 2010 meningkat. Hal ini disebabkan oleh beberapa faktor yaitu luas areal panen meningkat karena peralihan tanaman belum menghasilkan (TBM) menjadi tanaman menghasilkan (TM). Luas areal yang dipanen pada tahun 2007 seluas 1228 ha dengan produksi 0.88 ton/ha menjadi 2697 ha dengan produksi 9.99 ton/ha pada tahun 2010. Faktor lain yang menyebabkan meningkatnya produksi adalah jenis tanaman dan curah hujan.

Perseiapan panen. Menurut Pahan (2008) persiapan panen yang baik akan menjamin tercapainya target produksi dengan biaya panen seminimal mungkin. Divisi I kebun PAGE (Pelantaran Agro Estate) melakukan persiapan panen cukup baik diantaranya dalam kegiatan persiapan lahan, tenaga kerja, persiapan alat panen, dan taksasi produksi. Divisi I kebun PAGE masih mengalami beberapa masalah dalam persiapan panen.

Dalam kegiatan persiapan lahan sebelum panen di Divisi I masih mempunyai masalah yaitu lahan yang tergenang air, masih terdapat gulma di piringan sekitar pokok di beberapa, jalan yang tergenang air, dan titi panen yang masih kurang. Masalah-masalah tersebut sangat mengganggu kegiatan panen karena akses untuk kegiatan panen terganggu. Divisi I menyelesaikan masalah lahan yang tergenang air dengan memperdalam parit disekitar lahan yang tergenang sehingga drainase di daerah yang tergenang menjadi lebih baik. Gulma yang ada di piringan sekitar pokok dibersihkan secara manual dan kimia. Jalan yang tergenang air diperbaiki dengan menimbun tanah pada jalan yang tergenang air dan membuat parit di sekitar jalan tersebut. Sedangkan masalah kekurangan titi panen di Divisi I kebun PAGE diselesaikan dengan membeli titi panen kayu dan beton kepada kontraktor.

Taksasi produksi sangat penting untuk mendapatkan angka kerapatan panen (AKP). Menurut Fauzi, et al (2008) angka kerapatan panen adalah sejumlah angka yang menunjukkan tingkat kerapatan pohon matang panen dalam suatu areal. Tujuan taksasi produksi adalah untuk menentukan jumlah tenaga kerja yang dibutuhkan 
untuk menyelesaikan panen pada hari tersebut dan memperkirakan banyaknya jumlah unit truk yang dibutuhkan untuk pengangkutan TBS ke PKS sehingga AKP sangat penting dalam kegiatan panen. Hasil taksasi harus mendekati dengan realisasi, jika AKP mempunyai selisih yang besar dari realisasi maka akan menghambat kegiatan panen. Perbandingan hasil taksasi dan realisasi dapat dilihat pada Tabel 1.

Tabel 1. Perbandingan hasil taksasi dengan realisasi divisi I

\begin{tabular}{cccccccc}
\hline & \multicolumn{3}{c}{ Taksasi } & \multicolumn{4}{c}{ Aktual } \\
\cline { 2 - 8 } Blok Jumlah Jumlah & \multicolumn{3}{c}{ AKP Jumlah Jumlah } & AKP \\
& TBS & pokok & $(\%)$ & TBS & pokok & $(\%)$ \\
\hline D8 & 116 & 521 & 22.2 & 1801 & 5023 & 36 \\
E7 & 220 & 537 & 41.0 & 2605 & 5232 & 50 \\
E5 & 174 & 454 & 38.4 & 1411 & 3439 & 41 \\
D3 & 279 & 547 & 51.0 & 3399 & 5362 & 63 \\
\hline
\end{tabular}

Keterangan : AKP (Angka Kerapan Panen)

Bedasarkan hasil pangamatan penulis hasil taksasi AKP Blok E5 yang paling mendekati dengan realisasi yang mempunyai selisih $2.6 \%$ dengan jumlah pokok sampel $13 \%$ dari total populasi. Sedangkan pada blok lain hasil taksasi mempunyai selisih lebih dari $5 \%$ yang sesuai dengan peraturan perusahaan dan jumlah pokok sampel hanya $10 \%$ dari total populasi. Dapat disimpulkan bahwa semakin banyak sampel pokok terhadap dalam taksasi produksi maka semakin kecil selisih AKP dengan realisasi.

Kebutuhan Tenaga kerja panen Divisi I kebun PAGE dihitung berdasarkan luas areal yang dipanen, kerapatan buah dan kapasitas panen per hari. Secara teori kebutuhan tenaga potong buah Divisi I dengan dengan norma kerja 3 - 4 ha/HK adalah 45 orang sedangkan tenaga potong buah di Divisi satu berjumlah 43 orang. Kekurangan tersebut tidak terlalu menimbulkan hambatan. Divisi I mempunyai masalah pada tenaga potong buah ketika karyawan yang mengajukan cuti secara berbarengan sehingga mengakibatkan kekurangan tenaga kerja dan berpengaruh kepada hancak panen yang tidak selesai. Kebun PAGE membuat peraturan bahwa dalam 1 kemandoran tidak boleh ada karyawan yang mendapatkan cuti secara berbarengan. Dengan peraturan tersebut maka kebutuhan tenaga kerja panen terpenuhi.

Tenaga panen di Divisi I seluruhnya telah memiliki peralatan panen sendiri. Kendala yang terdapat pada alat-alat panen adalah ketika terjadi kerusakan pada angkong dan dodos. Kerusakan angkong biasanya adalah ban bocor sedangkan kerusakan dodos adalah mata dodos tumpul atau terlepas dari gagang dodos. Hal tersebut dapat menyebabkan kegiatan potong buah terhambat karena membutuhkan waktu untuk memperbaikinya. Dibutuhkan pengawasan mandor memeriksa peralatan panen para tenaga potong buah sebelum berangkat ke lahan.

Pelaksanaan panen. Kriteria panen sangat erat hubungannya dengan kualitas TBS di TPH. Menurut Sastrosayono (2003) persentase minyak (CPO) terhadap FFB (Fresh fruit bunch atau tandan buah segar) dari buah yang kurang masak (under ripe) relatif kecil, walaupun FFA (free fatty acid) atau asam lemak bebas (ALB) juga rendah. Buah yang terlalu masak (over ripe) bisa menimbulkan kerugian karena terlalu banyak buah yang berondol, sehingga untuk mengumpulkannya membutuhkan waktu yang lama dan kualitas minyak (CPO) dari buah yang terlalu masak tergolong buruk karena kandungan FFA cukup tinggi. Oleh karena itu, tenaga potong buah diharuskan memotong buah matang (ripe) agar mendapatkan kualitas dan kuntitas CPO yang optimum. Kualitas buah di TPH Divisi I dapat dilihat pada Tabel 2.

Bedasarkan hasil pengamatan penulis yang dilakukan di Divisi I kebun PAGE dapat dilihat bahwa kualitas buah yang dipanen sudah baik, terbukti dari buah yang matang $91.9 \%$ sisanya unripe $0 \%$, under ripe $1.5 \%$, over ripe $4.9 \%$, dan abnormal $1.7 \%$. Berdasarkan peraturan perusahaan kualitas buah Divisi I sudah cukup baik karena sudah memenuhi kriteria perusahaan. 
Tabel 2. Pengamatan kualitas buah di THP divisi I

\begin{tabular}{|c|c|c|c|c|c|c|c|c|}
\hline No & Kemandoran & Pemanen & Jumlah Tandan & Unripe & Under ripe & Ripe & Over ripe & Abnormal \\
\hline 1. & A & 1 & 126 & 0 & 2 & 118 & 5 & 1 \\
\hline 2. & & 2 & 156 & 0 & 1 & 146 & 5 & 4 \\
\hline 3. & & 3 & 100 & 0 & 0 & 90 & 8 & 2 \\
\hline 4. & & 4 & 130 & 0 & 1 & 121 & 6 & 2 \\
\hline 5. & & 5 & 133 & 0 & 1 & 122 & 8 & 2 \\
\hline 6. & B & 1 & 114 & 0 & 2 & 101 & 6 & 5 \\
\hline 7. & & 2 & 96 & 0 & 3 & 89 & 2 & 2 \\
\hline 8. & & 3 & 110 & 0 & 2 & 100 & 7 & 1 \\
\hline 9. & & 4 & 134 & 0 & 5 & 120 & 8 & 1 \\
\hline 10. & & 5 & 172 & 0 & 2 & 161 & 7 & 2 \\
\hline & Total & & 1271 & 0 & 19 & 1168 & 62 & 22 \\
\hline & Persentase (\%) & & 100.0 & 0 & 1.5 & 91.9 & 4.9 & 1.7 \\
\hline & Rata-rata & & 127.1 & 0 & 1.9 & 116.8 & 6.2 & 2.2 \\
\hline
\end{tabular}

Kehilangan produksi (losses) dapat terjadi akibat berondolan tidak dikutip. Di Divisi I kebun PAGE masih cukup banyak berondolan tidak dikutip. Jumlah berondolan yang tidak dikutip di Divisi I dapat dilihat pada Tabel 3.

Tabel 3. Jumlah berondolan yang tidak dikutip di divisi I

\begin{tabular}{|c|c|c|c|c|}
\hline No & Pemanen & Luas (ha) & $\begin{array}{c}\text { Jumlah } \\
\text { pokok }\end{array}$ & $\begin{array}{l}\text { Berondolan } \\
\text { tidak dikutip }\end{array}$ \\
\hline 1. & 1 & 1 & 143 & 71 \\
\hline 2. & 2 & 1 & 139 & 23 \\
\hline 3. & 3 & 1 & 131 & 33 \\
\hline 4. & 4 & 1 & 142 & 49 \\
\hline 5. & 5 & 1 & 130 & 84 \\
\hline 6. & 1 & 1 & 130 & 79 \\
\hline 7. & 2 & 1 & 130 & 115 \\
\hline 8. & 3 & 1 & 129 & 16 \\
\hline 9. & 4 & 1 & 133 & 121 \\
\hline 10. & 5 & 1 & 127 & 179 \\
\hline \multicolumn{2}{|r|}{ Total } & 10 & 1334 & 770 \\
\hline \multicolumn{2}{|r|}{ Rata-rata } & 1 & 133.4 & 77 \\
\hline
\end{tabular}

Bedasarkan pengamatan penulis rata- rata terdapat 77 berondolan /ha. Berondolan tersebut terdapat di piringan, ketiak pelepah, pasar pikul dan gawangan. Banyaknya jumlah berondolan yang tidak dikutip diakibatkan oleh tidak adanya tenaga pengutip berondolan sehingga tenaga potong buah bertugas memotong buah dan mengutip berondolan sekaligus. Oleh sebab itu tenaga potong buah mengalami kelelahan dan berkurangnya ketelitian dalam mengutip berondolan yang tidak terlihat jelas pada gawangan yang ditumbuhi banyak gulma. Menurut Pahan (2008) dalam satu tandan, terdapat 1000 - 3000 berondolan dengan berat berkisar 10 - 20 g/berondolan. Berondolan mempunyai kandungan minyak lebih dari $40 \%$. Oleh karena itu, berondolan harus dikutip bersih karena dapat menjadi salah satu penyebab losses yang cukup tinggi.

Kategori lain yang dapat menentukan kualitas panen adalah pemotongan gagang panjang. Kebun PAGE menerapkan gagang panjang maksimal $2.5 \mathrm{~cm}$. Pemotongan gagang panjang diterapkan karena gagang panjang dapat menyerap minyak pada saat pengolahan kelapa sawit sehingga dapat menimbulkan losses.

Tabel 4. Pengamatan gagang panjang di divisi I

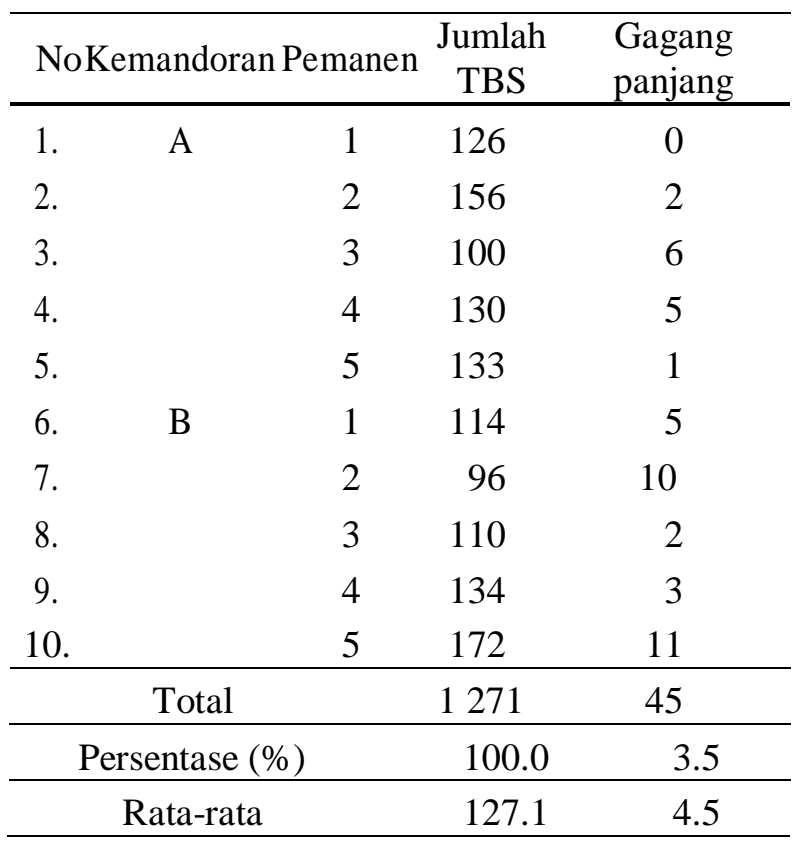


Berdasarkan Tabel 4 gagang panjang yang ada di Divisi I adalah 3.5\% yang artinya bahwa terdapat $3-4$ gagang panjang dari 100 TBS. Berdasarkan peraturan perusahaan gagang panjang seharusnya $0-1 \%$. Hal tersebut terjadi karena kurangnya ketelitian tenaga potong buah dan ketajaman alat yang kurang. Pemotongan gagang panjang seharusnya dilakukan di piringan tetapi kenyataannya masih banyak tenaga potong buah yang memotong gagang panjang di TPH sehingga menyebabkan adanya gagang TBS yang tidak dipotong. Alat potong harus dalam keadaan tajam sehingga pemotongan gagang panjang lebih mudah dan rapi.

Faktor lain yang menentukan kualitas kegiatan panen adalah TBS tinggal. TBS tinggal merupakan salah satu losses yang harus ditekan seminimal mungkin. Penulis melakukan pengamatan buah tinggal yang terdapat di Divisi I adalah $1 \%$. Hal ini disebabkan oleh beberapa faktor yaitu ketidaktelitian tenaga potong buah dalam mencari TBS yang berada di pinggir parit atau TBS matang yang terdapat pada pokok yang mempunyai banyak pelepah sehingga berondolan yang terlepas tidak terlihat akibat tersangkut di pelepah. Selain itu persiapan alat panen yang kurang sehingga menyebabkan TBS matang yang terdapat di pokok yang tinggi tidak dapat dipanen karena gagang dodos terlalu pendek.

Pengangkutan tandan buah segar (TBS). Pengangkutan TBS dan berondolan adalah kegiatan pengangkutan dari tempat pengumpulan hasil (TPH) ke pabrik kelapa sawit (PKS) pada setiap hari panen. Pada prinsipnya TBS harus diangkut secepatnya ke PKS untuk diolah pada hari itu juga. Hal ini dilakukan supaya minyak yang dihasilkan tetap bermutu baik. Kegiatan pengangkutan TBS dan berondolan adalah mata rantai dari proses produksi kelapa sawit. Ada empat hal yang menjadi sasaran kelancaran kegiatan pengangkutan buah yaitu menjaga agar asam lemak bebas (ALB) dibawah tiga persen, kapasitas atau kelancaran pengelolaan di pabrik, keamanan TBS di lapangan, dan biaya $(\mathrm{Rp} / \mathrm{kg}$ TBS) transport yang minimum. Menurut Setyamidjaja (2006) buah kelapa sawit yang sudah matang dan masih segar hanya mengandung $0,1 \%$ ALB. Buah-buah yang sudah memar atau pecah dapat mengandung asam lemak bebas sampai $50 \%$ hanya dalam waktu beberapa jam saja. Bahkan apabila buah dibiarkan begitu saja tanpa perlakuan khusus, dalam waktu 24 jam kandungan asam lemak bebas dapat mencapai 67\%. Kemudian Fauzi et al. (2008) menambahkan TBS harus segera diangkut ke pabrik untuk diolah yaitu maksimal 8 jam setelah panen. Oleh karena itu, pengangkutan tandan buah segar sangat mempengaruhi kulitas dan kuantitas dari TBS.

Tabel 5. Pengamatan proses pengangkutan buah divisi I

\begin{tabular}{cccccc}
\hline No & Tanggal & $\begin{array}{c}\text { Lama } \\
\text { muat } \\
\text { (menit) }\end{array}$ & $\begin{array}{c}\text { Lama } \\
\text { kirim } \\
\text { (menit) }\end{array}$ & $\begin{array}{c}\text { Bobot } \\
\text { (kg) }\end{array}$ & $\begin{array}{c}\text { Jumlah } \\
\text { (janjang) }\end{array}$ \\
\hline 1. & 18-Mar-11 & 80 & 58 & 8390 & 1520 \\
2. & 19-Mar-11 & 99 & 50 & 8360 & 1112 \\
3. & 06-Apr-11 & 155 & 56 & 7610 & 2025 \\
4. & 06-Apr-11 & 121 & 62 & 7850 & 1590 \\
5. & 11-Apr-11 & 102 & 55 & 9000 & 1050 \\
\hline & Rata-rata & 111.4 & 56.2 & 8242 & 1459.4 \\
\hline
\end{tabular}

Pada Tabel 5 pengamatan pengangkutan satu unit truk rata-rata dapat mengangkut 1459.4 janjang dengan berat $8242 \mathrm{~kg}$. Dapat dinyatakan bahwa unit truk kelebihan muatan yang seharusnya $7500 \mathrm{~kg}$ untuk satu unit dump truck (DT). Hal ini dapat mengakibatkan kerusakan pada truk dan biaya perawatan untuk truk meningkat.

Waktu yang dibutuhkan dalam pengangkutan TBS sangat berpengaruh dalam menjaga kualitas dan kuantitas TBS. Waktu yang dibutuhkan untuk memuat TBS hingga truk terisi penuh yaitu 111.4 menit dan waktu yang dibutuhkan untuk mengirim TBS hingga PKS adalah 56.2 menit dengan jarak kurang lebih 24 $\mathrm{km}$ sehingga total waktu yang dibutuhkan dalam pengangkutan buah hingga PKS adalah 167.6 menit.

\section{KESIMPULAN}

Kegiatan panen di kebun PAGE belum berjalan dengan baik. Hal ini dapat dilihat dengan masih adanya masalah-masalah yang terdapat pada persiapan panen, pelaksanaan panen, dan pengangkutan TBS. Tenaga potong buah memiliki pemahaman cukup baik terhadap kriteria matang buah. Hal tersebut dapat dilihat dengan kualitas buah yang dipanen yaitu unripe $0 \%$, under ripe $1.5 \%$, over ripe $4.9 \%$, abnormal $1.7 \%$ dan buah ripe $91.9 \%$ diatas standar yang ditentukan oleh perusahaan. Tetapi masih ada pelanggaran yang dilakukan oleh tenaga potong buah seperti panjang gagang yang masih lebih dari $2.5 \mathrm{~cm}$, berondolan yang tidak dikutip masih $77 \mathrm{butir} / \mathrm{ha}$ yang seharusnya maksimal $30 \mathrm{butir} / \mathrm{ha}$, dan masih adanya buah tinggal yang seharunsya $0 \%$. Pelanggaran-pelanggaran yang dilakukan oleh 
tenaga potong buah diatasi dengan sistem denda agar pelanggaran-pelanggaran semakin menurun.

\section{DAFTAR PUSTAKA}

Arianto, E. 2008. Pertumbuhan produksi minyak sawit Indonesia 1964-2007. [internet] [diunduh 18 Nov 2010]. Tersedia pada http://www.pdf.searchengine.com.

[DIRJENBUN] Direktorat Jenderal Perkebunan. 2010. Peran Strategis Kelapa Sawit Indonesia Tahun 2008. [internet] [diunduh 11 Jan 2011]. Tersedia pada http:// www.ditjenbun.deptan.go.id.

Fauzi, Y., Y. Widyastuti, I. Setyawibawa, R. Hartono. 2008. Kelapa Sawit. Jakarta (ID) : Penebar Swadaya. 168 hal.

Lubis, A. U. 1992. Kelapa Sawit ( Elaeis guineensis Jacquin.) di Indonesia. Pusat Penelitian Perkebunan Marihat-Bandar Kuala. Marihat Ulu. 435 hal.

Mangoensoekarjo, S., H. Semangun. 2008. Manajemen Agribisnis Kelapa
Sawit. Yokyakarta (ID) : Gajah Mada University Press. 605 hal.

Pahan, I. 2008. Kelapa Sawit Manajemen Agribisnis dari Hulu hingga Hilir. Jakarta (ID) : Penebar Swadaya. 536 hal.

Sastrosayono, S. 2003. Budidaya Kelapa Sawit. Jakarta (ID): Agromedia Pustaka. 65 hal.

Setyamidjaja, D. 2006. Kelapa Sawit: Teknik Budidaya, Panen, dan Pengolahan. Yogyakarta (ID): Kanisius. 127 hal.

Sunarko. 2007. Petunjuk Praktis Budi Daya dan Pengolahan Kelapa Sawit. Jakarta (ID): Agromedia Pustaka. 70 hal.

Departemen Agronomi dan Hortikultura. 2010. Pedoman Penulisan Skripsi Program Pendidikan Sarjana. Departemen Agronomi dan Hortikultura Fakultas Pertanian Institut Pertanian Bogor. 58 hal. 